\title{
A Role for the Eph Ligand Ephrin-A3 in Entorhino-Hippocampal Axon Targeting
}

\author{
Eckart Stein, ${ }^{1}$ Nicolai E. Savaskan, ${ }^{1}$ Olaf Ninnemann, ${ }^{1}$ Robert Nitsch, ${ }^{1}$ Renping Zhou, ${ }^{2}$ and Thomas Skutella \\ 1/nstitute of Anatomy, Department of Cell and Neurobiology, Humboldt University Hospital (Charité), 10098 Berlin, \\ Germany, and 2Laboratory for Cancer Research, Department of Chemical Biology, College of Pharmacy, Rutgers \\ University, Piscataway, New Jersey 08855
}

Neurons of layers II and III of the entorhinal cortex constitute the major afferent connection of the hippocampus. The molecular mechanisms that target the entorhinal axons to specific layers in the hippocampus are not known. EphA5, a member of the Eph receptor family, which has been shown to play critical roles in axon guidance, is expressed in the entorhinal cortex, the origin of the perforant pathway. In addition, ligands that interact with EphA5 are expressed in distinct hippocampal regions during development of the entorhino-hippocampal projection. Of these ligands, ephrin-A3 mRNA is localized both in the granular cell layer of the dentate gyrus and in the pyramidal cell layer of the cornu ammonis, whereas ephrin-A5 mRNA is only expressed in the pyramidal cell layer of the cornu ammonis. In the dentate gyrus, the ligand protein is not present in the termination zone of the entorhinal efferents (the outer molecular

The entorhinal cortex (EC) is the major integration zone of the neocortex, distributing its efferents to the hippocampus via the perforant and alvear pathways in a highly organized manner (Steward and Scoville, 1976; Tamamaki and Nojyo, 1993; Witter, 1993). Entorhinal fibers originating from stellate neurons in layer II and pyramidal cells in layer III terminate on distal dendritic segments in the outer molecular layer of the fascia dentata and stratum lacunosum moleculare of the hippocampus proper, on both sides of the hippocampal fissure. The entorhinal efferents thereby form a highly demarcated lamina at a certain distance parallel to the granular cell layer at a right angle to the apical dendrites (Fig. 1). In contrast, hippocampal commissural and associational fibers occupy the inner third of the molecular layer. This leads to the assumption that specific guidance molecules are expressed in the inner and outer molecular layers determining the ingrowth of these fiber systems.

A number of diffusible and membrane-associated attractive or repulsive axon guidance molecules have been identified. These include netrins, semaphorins, and Eph tyrosine kinase receptors and their ligands (for review, see Culotti and Kolodkin, 1996; Friedman and O‘Leary, 1996; Tessier-Lavigne and Goodman, 1996; Zhou, 1998). At present, it is not known whether these guidance molecules function in the lamina-specific axon targeting

\footnotetext{
Received Jan. 27, 1999; revised July 23, 1999; accepted July 30, 1999.

Drs. Stein and Savaskan contributed equally to this work.

This work was supported by the Deutsche Forschungsgemeinschaft (SK 49/3-1) and SFB 515.

Correspondence should be addressed to Dr. Thomas Skutella, Institute of Anatomy, Department of Cell and Neurobiology, Humboldt University Hospital Charité, Philippstrasse 12, 10098 Berlin, Germany.

Copyright (C) 1999 Society for Neuroscience $\quad 0270-6474 / 99 / 198885-09 \$ 05.00 / 0$
}

layer of the dentate gyrus) but is concentrated in the inner molecular layer into which entorhinal efferents do not grow. We used outgrowth and stripe assays to test the effects of ephrin-A3 and ephrin-A5 on the outgrowth behavior of entorhinal axons. This functional analysis revealed that entorhinal neurites were repelled by ephrin-A3 but not by ephrin-A5. These observations suggest that ephrin-A3 plays an important role in the layer-specific termination of the perforant pathway and that this ligand may interact with the EphA5 receptor to restrict entorhinal axon terminals in the outer molecular layer of the dentate gyrus.

Key words: axonal targeting; entorhino-hippocampal system; dentate gyrus; development; Eph receptors; ephrins; axon outgrowth; stripe assay

of the entorhino-hippocampal pathway. Recent studies have shown that the Eph family of tyrosine kinases and their ligands are involved in the specification of topographic maps in the brain (for review, see Friedman and O'Leary, 1996; Flanagan and Vanderhaeghen, 1998; Holt and Harris, 1998; Zhou, 1998) and may also play a role in the development of hippocampal efferent and afferent pathways. It has been shown that several Eph receptors and ephrins are expressed during development of the hippocampal system and its efferent and afferent connections (Taylor et al., 1994; Zhou et al., 1994; Mori et al., 1995; Gao et al., 1996; Zhang et al., 1996, 1997; Kozlosky et al., 1997; Martone et al., 1997; Zhou, 1997). For example, Mori et al. (1995) and Martone et al. (1997) have shown by in situ hybridization or immunohistochemistry that EphA4 is localized in the entorhinal cortex, subiculum, and hippocampus during development. EphA5 is highly expressed in all limbic structures, including the entorhinal cortex and the pyramidal cell layer of the cornu ammonis of the hippocampus during development (Taylor et al., 1994; Zhou et al., 1994; Zhang et al., 1996; Zhou, 1997). In contrast to most members of the EphA subfamily, EphA6 shows only a very weak expression during development of the brain but is highly expressed in adult hippocampus (Maisonpierre et al., 1993). Also, EphA7 has been localized in the hippocampus but not in the entorhinal cortex (Ciossek et al., 1995). In addition, several EphA subfamily ligands, including ephrin-A1, ephrin-A3, ephrin-A4, and ephrin-A5, are expressed during hippocampal development (Carpenter et al., 1995; Zhang et al., 1996; Kozlosky et al., 1997; Zhou, 1998).

In this paper, we examine the roles of EphA5, ephrin-A3, and ephrin-A5 in the development of the entorhino-hippocampal 

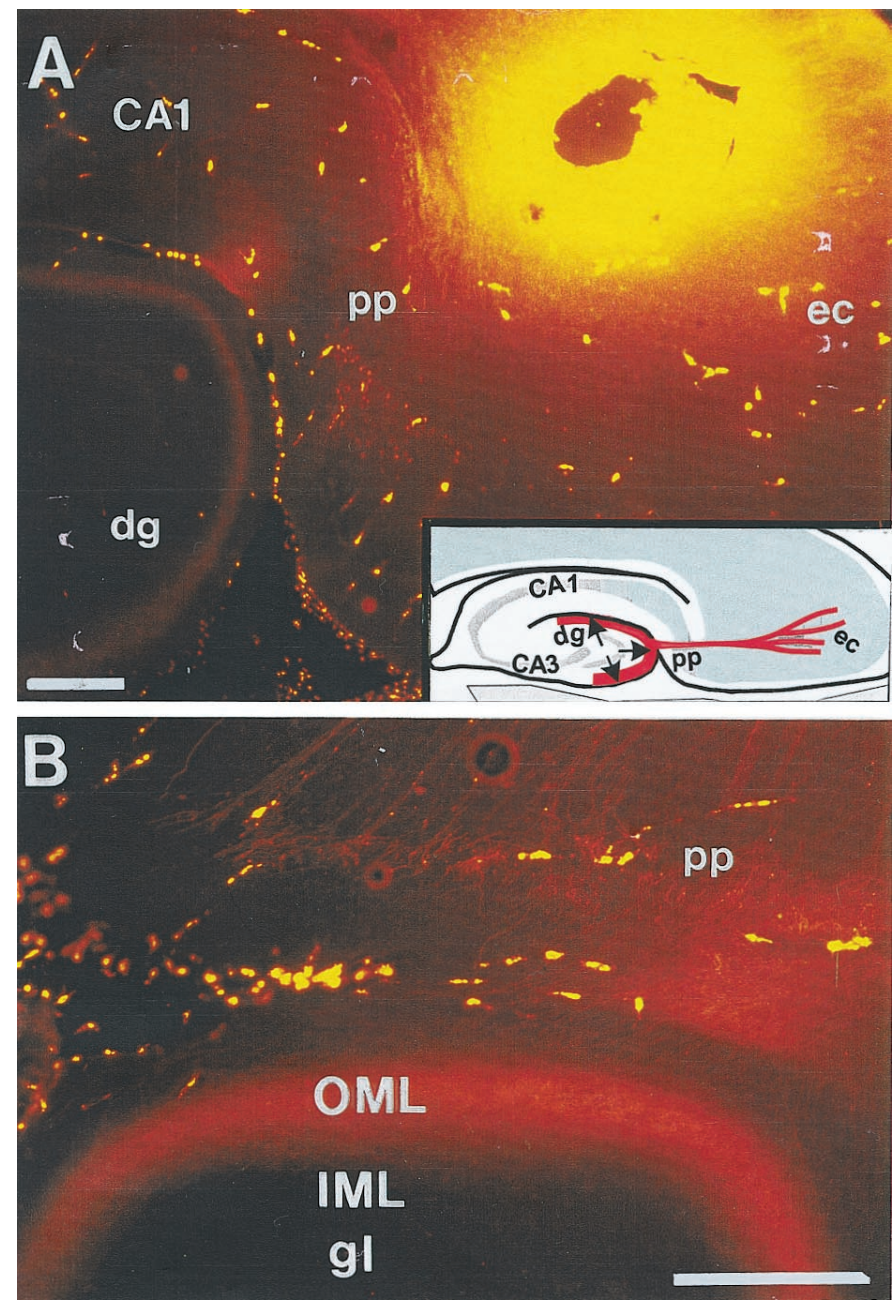

Figure 1. Lamina-specific entorhino-hippocampal projection visualized by tracing with the fluorescent dye (Mini Ruby) injected into the ipsilateral entorhinal cortex of postnatal day 15 rat (horizontal section, $100 \mu \mathrm{m}$ ). Note that entorhinal fibers enter the outer molecular layer $(O M L)$ of the dentate gyrus $(A, B)$, and no labeled entorhinal fibers can be observed in the inner molecular layer $(I M L)$. Inset, Schematic illustration of the perforant pathway. $C A$, Cornu ammonis; $d g$, dentate gyrus; $e c$, entorhinal cortex.; $p p$, perforant pathway. Scale bar: $A, B, 250 \mu \mathrm{m}$.

system. In situ hybridization and binding studies with a fusion protein of the EphA5 receptor domain with alkaline phosphatase (AP) show that the two ligands are expressed in the hippocampus and the receptor EphA5 in the entorhinal cortex. Outgrowth and stripe assays show that entorhinal neurites are specifically repelled by ephrin-A3. These results reveal the potential role of the interaction of EphA5 and ephrin-A3 in the developmental construction of the entorhino-hippocampal connection.

\section{MATERIALS AND METHODS}

\section{Tracing of the perforant pathway}

Mini Ruby (Molecular Probes, Eugene, OR) was applied stereotactically into the entorhinal cortex of postnatal day 15 (P15) rats, using a conventional spinal needle consisting of an inner needle sheathed in a metal envelope. The most distal tip of the envelope was cut in such a way to allow the inner needle to contact only the entorhinal region but not brain regions above the entorhinal cortex and meninges. By doing this, labeling of meningeal macrophages and brain regions other than the target area could be minimized. The tracer was applied with the inner needle brought into contact with only a few crystals of Mini Ruby and guided within the envelope into the entorhinal cortex (Molecular Probes). This gives better results in myelinated axons than with Dye I tracing, as described previously (Bechmann and Nitsch, 1997). One day after tracer application, animals were transcardially perfused, and horizontal sections $(100 \mu \mathrm{m})$ of the brain were cut on a vibratome.

In situ hybridization. For in situ hybridization experiments, NMRI mice were decapitated, and brains were dissected from embryonic day 17 (E17)-P10 and adult animals and frozen in liquid nitrogen. Horizontal cryostat sections $(20 \mu \mathrm{m})$ were fixed in $4 \%$ formaldehyde and washed in $0.1 \mathrm{~m}$ phosphate buffer, $\mathrm{pH}$ 7.4.

Antisense oligonucleotides 5'GCGCTGTAACGCTGGAACTTCT CGGAGAACTTGATGG GGCTG3' complementary to bases 355-397 of the mouse ephrin-A3 cDNA (Zhang et al., 1996), 5'GCTTGATTGGGATCTTCATAAGTGTGCGGATCAATATAGGTT3' complementary to bases 1878-1920 of the mouse EphA5 cDNA (Zhou et al., 1994), and an antisense riboprobe transcribed from a $0.7 \mathrm{~kb}$ human ephrin-A5 cDNA cloned in pBluescript (Zhang et al., 1996) were used for in situ hybridization. Sense probes served as controls and revealed no specific hybridization.

Oligonucleotides were end-labeled using terminal deoxynucleotide transferase (Boehringer Mannheim, Indianapolis, IN) and $\left[\alpha^{-}{ }^{35} \mathrm{~S}\right] \mathrm{dATP}$ $(12.5 \mu \mathrm{Ci} / \mu \mathrm{l}$; DuPont NEN, Boston, MA) according to the manufacturer's protocol. Hybridization was performed according to Zhang et al. (1996) for $16 \mathrm{hr}$ at $42^{\circ} \mathrm{C}$ in a humidified chamber, after which the slides were washed two times for $30 \mathrm{~min}$ in $1 \times \mathrm{SSC}$ at $56^{\circ} \mathrm{C}$ and one time for $5 \mathrm{~min}$ in $0.5 \times \mathrm{SSC}$ at room temperature. Finally, the sections were rinsed in $\mathrm{H}_{2} \mathrm{O}$ at room temperature and dehydrated.

For riboprobe preparation, the vector carrying the corresponding cDNA was digested with appropriate restriction enzymes, and the linearized vector was incubated for $2 \mathrm{hr}$ at $37^{\circ} \mathrm{C}$ in $30 \mu \mathrm{l}$ of a reaction mix (containing: $1 \times$ reaction buffer; $10 \mathrm{mM}$ ATP, GTP, and CTP each; 0.4 mM P ${ }^{32}$ UTP; $1 \times$ BSA; 100 mm DTT; 32 U RNaseA-inhibitor (Boehringer Mannheim); and 50 U T7 RNA polymerase (Boehringer Mannheim) for antisense probes or $50 \mathrm{U}$ T3 RNA polymerase (Boehringer Mannheim) for sense riboprobes). The reactions were then treated with DNaseI (7.5 U for $30 \mathrm{~min}$ at $37^{\circ} \mathrm{C}$; Boehringer Mannheim), and the riboprobes were partially degraded with $1 / 10 \mathrm{vol}$ of $\mathrm{NaOH}$ for $10 \mathrm{~min}$ at $4^{\circ} \mathrm{C}$ and neutralized with 2:10 vol of acetate. After hybridization for 16 $\mathrm{hr}$ at $52^{\circ} \mathrm{C}$ in a humidified chamber, the slides were washed one time in $\mathrm{H}_{2} \mathrm{O}$ at room temperature and then incubated with $20 \mu \mathrm{g} / \mathrm{ml}$ RNase-A in a buffer containing $10 \mathrm{~mm}$ Tris- $\mathrm{HCl}, \mathrm{pH} 8.0,1 \mathrm{~mm}$ EDTA, and $500 \mathrm{~mm}$ $\mathrm{NaCl}$ for $15 \mathrm{~min}$ at $37^{\circ} \mathrm{C}$. The slides were washed one time in $\mathrm{H}_{2} \mathrm{O}$, two times in $1 \times \mathrm{SSC}$ at $56^{\circ} \mathrm{C}$ for $30 \mathrm{~min}$ each, and two times in $0.1 \times \mathrm{SSC}$ at $56^{\circ} \mathrm{C}$ for $30 \mathrm{~min}$ each. Slides were exposed for 1 week to Kodak (Eastman Kodak, Rochester, NY) X-OMAT AR x-ray films.

\section{EphA5-AP fusion protein binding}

EphA5-AP binding to ligand molecules was assayed as described previously (Gao et al., 1996). Briefly, to study whether the ligands are expressed in the target tissues, we investigated the expression of EphA5 ligands using a ligand-affinity probe, EphA5-AP, which consisted of the extracellular domain of Eph-A5 fused in frame with a heat-stable human placental alkaline phosphatase. To detect expression of EphA5 ligand proteins, rat embryo sections (20 $\mu \mathrm{m}$ thickness) were prepared on a cryostat and fixed with methanol at $-80^{\circ} \mathrm{C}$ for $5 \mathrm{~min}$. After rehydrating the sections in PBS, they were equilibrated in HBSS without $\mathrm{Ca}^{2+} / \mathrm{Mg}^{2+}$ for $5 \mathrm{~min}$ and incubated in HBSS supplemented with $20 \%$ fetal calf serum for $2 \mathrm{hr}$. The sections were then overlaid with concentrated conditioned medium containing the recombinant protein diluted in HBSS plus 20\% FCS for 90 min. After one wash with HBSS and three washes with TBS (20 mm Tris- $\mathrm{HCl}$ and $135 \mathrm{~mm} \mathrm{NaCl}, \mathrm{pH} 7.5)$ for $5 \mathrm{~min}$ each, the sections were equilibrated with PBS for $5 \mathrm{~min}$ and fixed in $3.7 \%$ formaldehyde in PBS for $5 \mathrm{~min}$. After one wash with PBS, endogenous phosphatases were heat-inactivated at $65^{\circ} \mathrm{C}$ for $50 \mathrm{~min}$. After equilibrating with AP buffer (100 mM Tris, $100 \mathrm{~mm} \mathrm{NaCl}$, and $5 \mathrm{mM} \mathrm{MgCl}_{2}, \mathrm{pH}$ 9.5), bound EphA5-AP fusion proteins were visualized with a staining solution containing $34 \mathrm{mg} / \mathrm{ml}$ nitro-blue-tetrazolium and $18 \mathrm{mg} / \mathrm{ml}$ 5-bromo-4-chloro-3-indolylphosphate (Boehringer Mannheim) in AP buffer. The specificity of the EphA5-AP binding was determined by competition through excess of unlabeled EphA5, which abolished the binding.

\section{Neurite outgrowth assay}

For assaying growth inhibition of axons from primary culture, entorhinal cortex, hippocampus, and cerebellum were dissected, and cells were dissociated with $0.25 \%$ trypsin. Neurons $\left(4 \times 10^{5}\right.$ cells per well $)$ were 

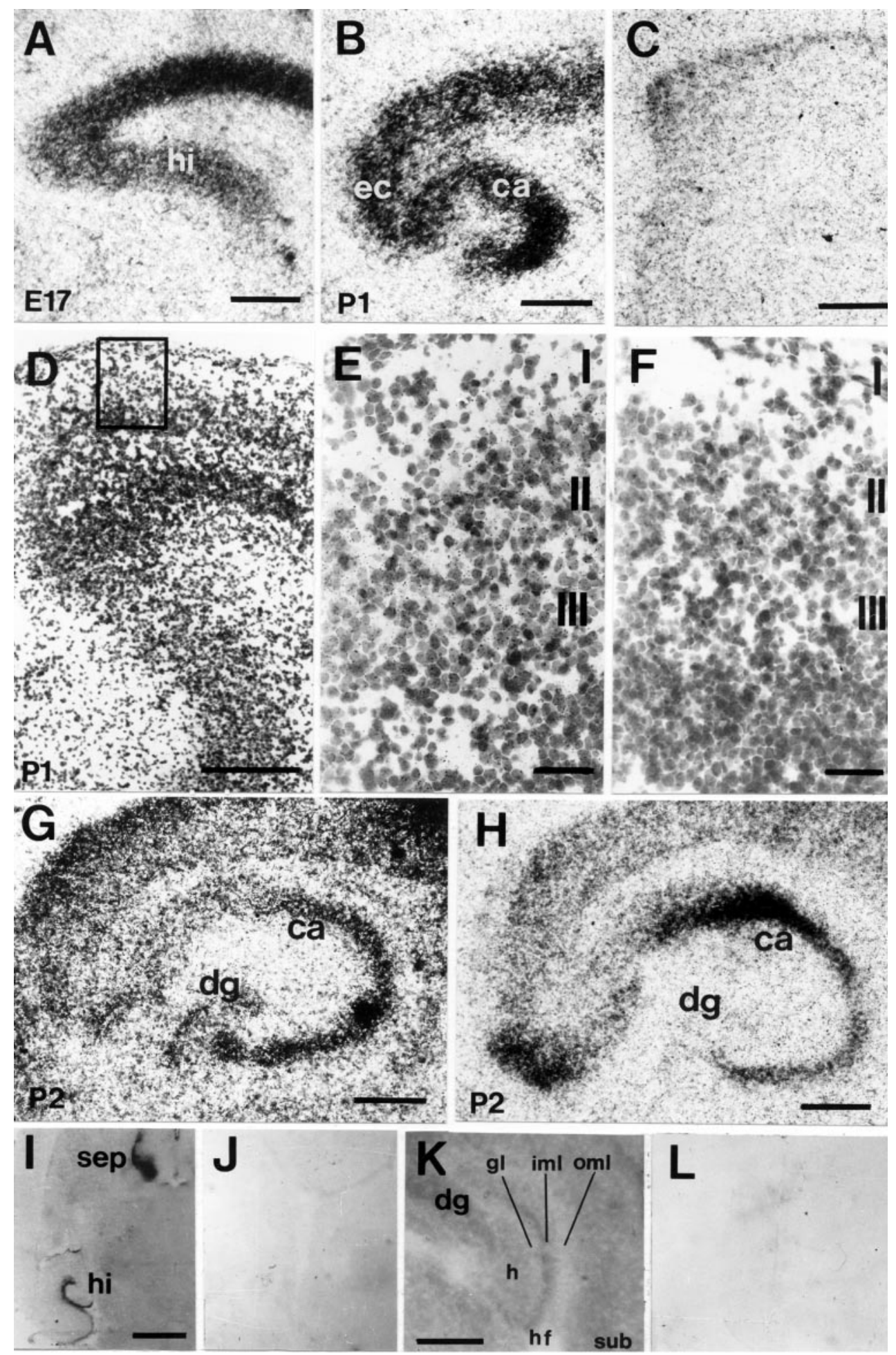

Figure 2. Distribution of EphA5 $(A-F)$, ephrin-A3 $(G)$, ephrin-A5 $(H)$ mRNA and EphA5-AP fusion protein binding ( $I-L)$ in the developing entorhino-hippocampal system on horizontal sections. $A$, At E17, strong hybridization signals for EphA5 mRNA signals were found in the cortex and hippocampal primordium. $B$, At P1, EphA5 expression was localized in the cortex, EC, and subiculum. In the hippocampus, strong hybridization signals were present in the pyramidal cell layers of CA1-CA3. C, Sense control for EphA5 in situ hybridization showed no specific labeling. $D$, Emulsion-coated EphA5 in situ hybridization of the entorhinal cortex; the boxed area is shown in higher magnification in E. E, At P1, EphA5 expression was localized to layers II and III of the EC, whereas no specific labeling could be observed with the sense control $(F)$. $G$, At P2, ephrin-A3 mRNA was expressed in the cortex, the CA1-CA3 regions, and the granular cell layer of the dentate gyrus. $H$, Ephrin-A5 mRNA was localized in the CA pyramidal cell layers from P2 onward but not in the dentate gyrus. I, EphA5-AP fusion protein binding could be localized in the hippocampus and the septum, whereas negative control using alkaline phosphatase detection alone did not show binding signals $(J)$. $K$, In the hippocampus, EphA5-AP fusion protein binding was strongest in the inner molecular layer of the dentate gyrus and low in the outer molecular layer; no specific labeling could be observed with the negative control $(L)$. hi, Hippocampus; sep, septum; $C A$, Cornu ammonis; $d g$, dentate gyrus; $e c$, entorhinal cortex; $g l$, granular layer; oml, outer molecular layer; $i m l$, inner molecular layer; $h f$, hippocampal fissure; sub, subiculum. Scale bars: $A-C, G, H, K, 500 \mu \mathrm{m} ; D, I, 1 \mathrm{~mm} ; E, F, 100 \mu \mathrm{m}$. 

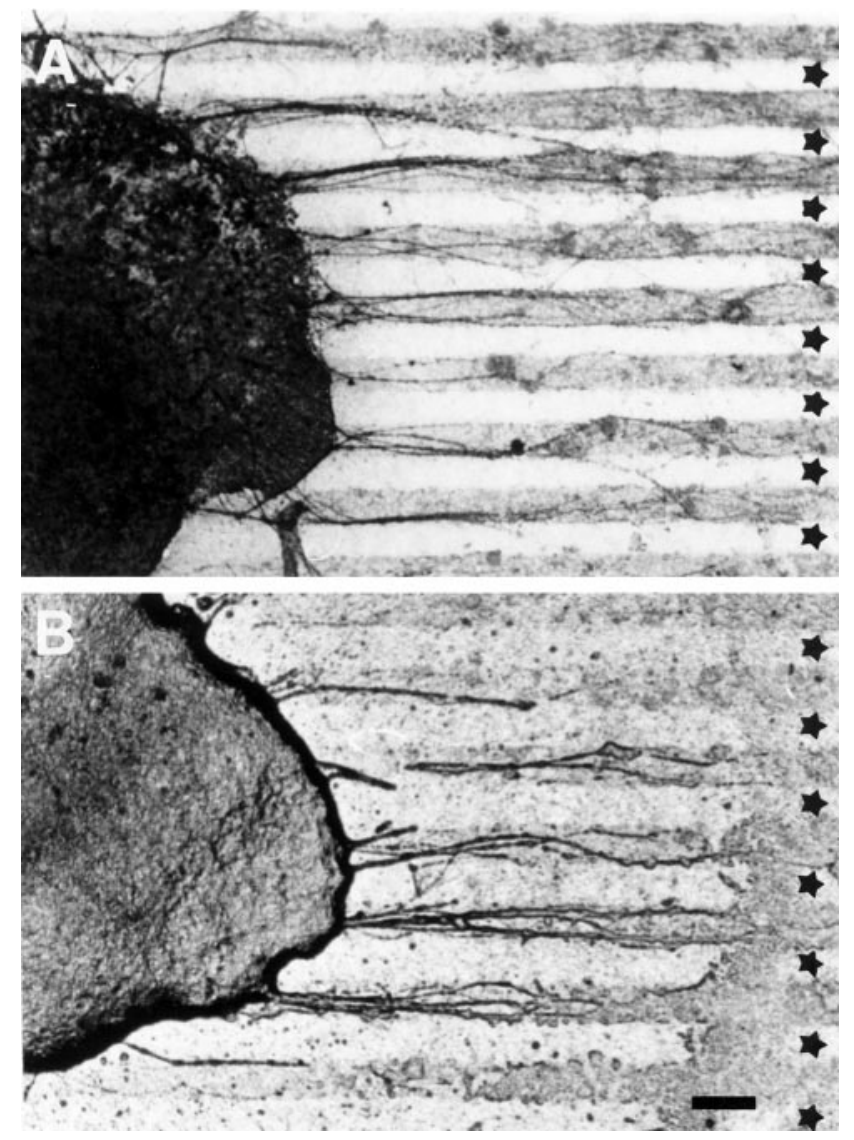

Figure 3. A, Entorhinal neurites show a strong preference for membranes from the outer molecular layer of the hippocampus when given a choice between these and inner molecular-granular layer membranes $(n=24)$. B, Entorhinal choice behavior was independent of membrane lane order $(n=12)$. $\star$, Inner molecular-granular layer. Scale bar, $100 \mu \mathrm{m}$.

plated in 24-well dishes onto confluent monolayers of ephrin-A3- or ephrin-A5-expressing NIH 3T3 cells or control NIH 3T3 cells transfected with the vector in DMEM supplemented with fetal bovine serum $(10 \%)$, penicillin $(50 \mathrm{ng} / \mathrm{ml})$, and streptomycin $(50 \mu \mathrm{g} / \mathrm{ml})$, cultivated for $3 \mathrm{~d}$ and fixed in $4 \%$ paraformaldehyde in PBS. After fixation, neuronal processes were incubated with an anti-neurofilament $160 \mathrm{kDa}$ antibody obtained from Boehringer Mannheim (catalog \#814334) in a concentration of $5 \mu \mathrm{g} / \mathrm{ml}$, followed by an subsequent incubation in avidin-biotin peroxidase complex (Vectastain ABC kit; Vector Laboratories, Burlingame, CA) and visualized with $3^{\prime}-3^{\prime}$ diaminobenzidine as a chromogen. Random fields were selected, and all anti-neurofilament antibody-stained neurites growing out from aggregates and single cells in these fields were scored. At least 200 fields were surveyed for each sample assayed, and the experiments were repeated a minimum of three times.

\section{Explant outgrowth and stripe assay}

Explant preparation. Fetuses and offspring of timed pregnant E17-E18 Wistar rats were used. To collect embryonic tissue, pregnant rats were anesthetized with Nembutal $(5 \mathrm{mg} / 100 \mathrm{mg}$ ), and embryos were removed from the uterus. Embryos were placed in cold, oxygenated L15 medium (Life Technologies, Gaithersburg, MD) supplemented with $0.6 \%$ glucose. Animals were killed by decapitation, the brains were dissected out, and the meninges were removed. Horizontal sections were cut at $400 \mu \mathrm{m}$ in cold, oxygenated PBS with a vibratome, and entorhinal explants from the superficial layers were dissected out with tungsten needles under binocular optics with $40 \times$ magnification. After dissection, the explants were placed in suspension culture in a $5.5 \% \mathrm{CO}_{2}$ humidified incubator in DMEM-F-12 supplemented with $2 \mathrm{~mm}$ glutamine, $0.6 \%$ glucose, 100 $\mathrm{U} / \mathrm{ml}$ penicillin, $100 \mu \mathrm{g} / \mathrm{ml}$ streptomycin, $5 \%$ heat-inactivated rat serum, $10 \%$ heat-inactivated fetal bovine serum, and $10 \mu \mathrm{M}$ cytosine arabinoside
Table 1. Degree of entorhinal axon choice for membranes from outer molecular layer

\begin{tabular}{lllllll}
\multicolumn{7}{c}{ Category of axon choice } \\
\cline { 2 - 7 } $\begin{array}{llllll}\text { Substrates } \\
\text { compared }\end{array}$ & $\begin{array}{l}\text { Not } \\
\text { classified }\end{array}$ & $\begin{array}{l}\text { No } \\
\text { preference }\end{array}$ & $\begin{array}{l}\text { Slight } \\
\text { prefer- } \\
\text { ence }\end{array}$ & $\begin{array}{l}\text { Clear } \\
\text { prefer- } \\
\text { ence }\end{array}$ & $n$ & Significance \\
\hline OML/GCL & 1 & 1 & 9 & 13 & 24 & $p=0.001$ \\
GCL/OML & 0 & 2 & 3 & 7 & 12 & $p=0.01$ \\
\hline
\end{tabular}

Not classified: Explants that did not show any outgrowth; classification of choice preferences is described in Material and Methods. In the two sets of experiments OML/GCL and GCL/OML describe the order of membrane application. $n$, Number of explants; OML, outer molecular layer; GCL, inner molecular/granular layer.

to control proliferation of non-neuronal cells. Entorhinal explants were used for the assays on the same day.

Preparation of membranes. Membrane suspensions were prepared from NIH 3 T3 cells expressing ephrin-A3 or ephrin-A5 or from microdissected hippocampal regions of the pig (6 months old) from which it is possible to dissect the outer molecular layer and the inner moleculargranular layer of the dentate gyrus. The membranes were prepared according to a protocol of Walter et al. (1987a,b). All solutions used were sterile, $4^{\circ} \mathrm{C}, \mathrm{pH} 7.4$, and supplemented with protease inhibitors as described previously (Simon and O'Leary, 1992). Cells were homogenized in homogenization buffer (10 mM Tris-HCI, pH 7.4, $1.5 \mathrm{mM} \mathrm{CaCl}_{2}$, and $1 \mathrm{~mm}$ spermidine; Serva Feinbiochemica, Heidelberg, Germany) by pressing the tissue first through a narrow pipette and then two to three times through syringe needles. The homogenate was layered on top of a step gradient of 50 and $5 \%$ sucrose in homogenization buffer and centrifuged for $10 \mathrm{~min}$ at $50,000 \times \mathrm{g}$ at $4^{\circ} \mathrm{C}$ in an $\mathrm{SW} 50 \mathrm{~L}$ rotor (Beckman Instruments, Fullerton, CA). Cytoplasmic and mitochondrial membrane fragments formed a turbid layer at the boundary between 5 and $50 \%$ sucrose, while nuclei were pelleted. The membrane fragments were collected with a syringe and washed with PBS. The concentration of the membrane suspension was adjusted to a concentration of 100-200 $\mu \mathrm{g} / \mathrm{ml}$ protein as determined by a modified Bradford method with bovine serum albumin as standard. For phosphatidylinositol (PI)-specific phospholipase C (PLC) treatment, membrane suspensions were adjusted to an optical density of 0.5 (measured at $220 \mathrm{~nm}$ ) in Tris buffer containing 1.5 $\mathrm{mM} \mathrm{CaCl}{ }_{2}$ and protease inhibitors. The membrane suspensions were then treated with PI-PLC (1 U/ml; ICN Biochemicals, Montréal, Québec, Canada) for $1 \mathrm{hr}$, washed in cold PBS containing protease inhibitors, and resuspended in the same PBS solution.

Explant outgrowth assay. Entorhinal cortex explants were plated on membranes prepared from the ephrin-A3, ephrin-A5, or the mocktransfected NIH 3 T3 cells. Uniform membrane carpets for outgrowth measurements were made by pipetting $150 \mu \mathrm{l}$ of membrane suspension $(100-200 \mu \mathrm{g} / \mathrm{ml})$ onto a filter placed over a uniform mesh and applying suction for up to $3 \mathrm{~min}$. The total outgrowth length of all fluorescencestained processes from the entorhinal explants was scored, and data from each experimental group were pooled and analyzed by ANOVA and Mann-Whitney $U$ test.

Stripe assay. Membrane stripes were prepared with membranes obtained either from ephrin-A3, ephrin-A5, or mock-transfected NIH 3T3 cells on polycarbonate filters precoated with laminin. Membrane extracts from the outer molecular layer and inner molecular-granular layer were prepared using the same protocol. The membrane carpets were then placed on sterile, porous $(0.4 \mu \mathrm{m})$ membranes (Millicell-CM; Millipore, Eschborn, Germany) and transferred into a $35 \mathrm{~mm}$ tissue culture dish with $1.5 \mathrm{ml}$ culture medium. Explants were positioned on the membrane carpets using forceps. Cultures were maintained in a $5.5 \% \mathrm{CO}_{2}$ humidified incubator for up to $5 \mathrm{~d}$.

Analysis of outgrowth preference. Neurites growing out from the explants were visualized with a fluorescent vital dye, 5 and 6-carboxyfluorescein diacetate, succinimidyl ester (Molecular Probes), which labels all living cells and their processes, or by immunolabeling with a neurofilament antibody (Boehringer Mannheim). A $6.15 \mathrm{mg} / \mathrm{ml}$ stock solution of dye was diluted 1:300 in PBS. Culture medium was removed from the dishes $5 \mathrm{~d}$ after the explants were placed on the carpets, and 1-2 $\mathrm{ml}$ of the dye solution was added for $2 \mathrm{~min}$. To inhibit photobleaching, the dye solution was then replaced with a solution of 5 mM $p$-phenylenediamine (Eastman Kodak) in PBS. Neurite growth from 

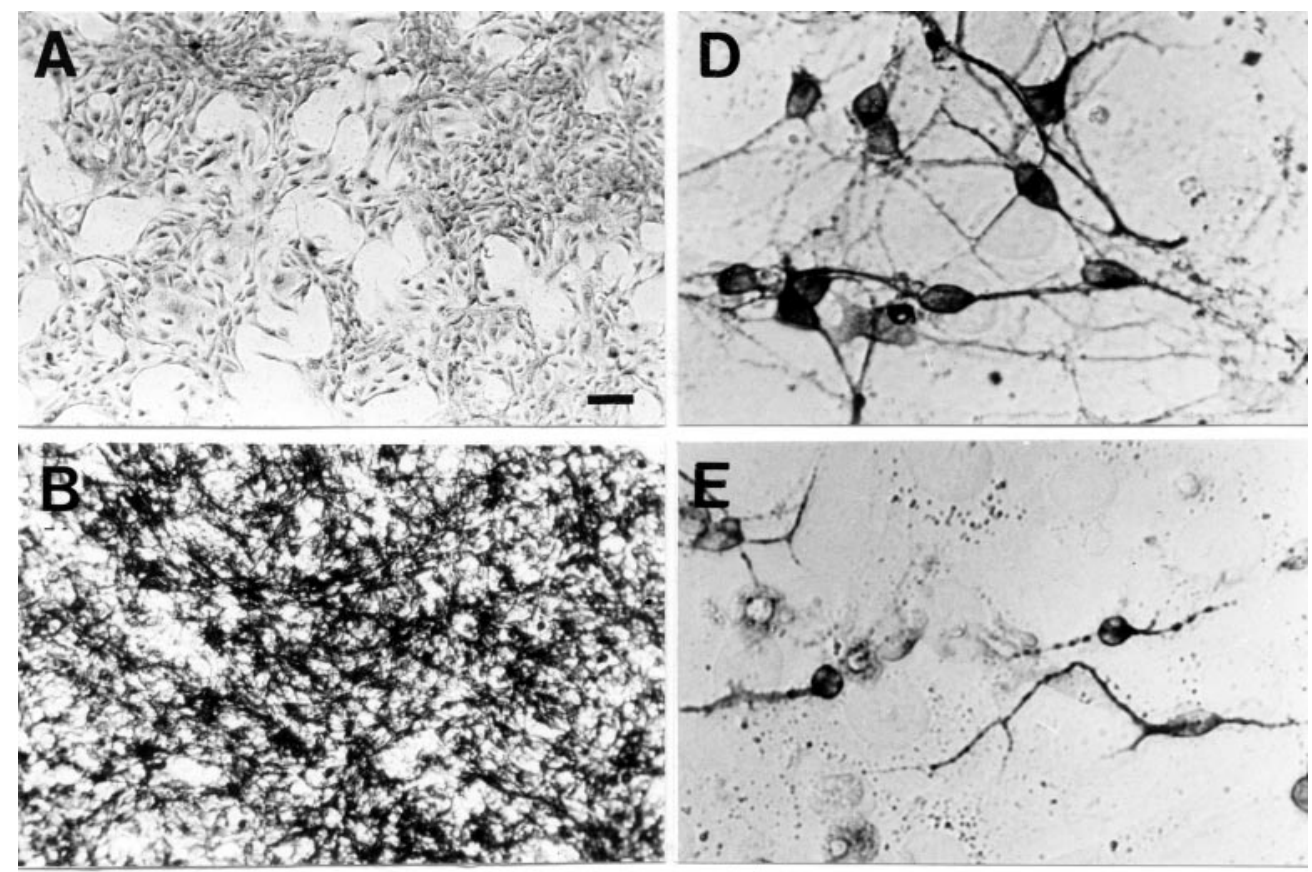

Figure 4. Inhibition of entorhinal neurite elongation by ephrin-A3. $A$, EphA5-AP staining was absent on the mock-transfected cells, whereas ephrin-A5- $(B)$ and ephrin-A3- $(C)$ transfected cells showed a strong signal, indicating high levels of expression of the corresponding ligand. E18 entorhinal cortex neurons were supercultivated on a confluent layer of 3 T3 mock- $(D)$, ephrin-A5- $(E)$, or ephrin-A3- $(F)$ transfected cells. $D-F$, Neurites were stained with anti-neurofilament antibody. Neurons and their processes are darkly stained, and the underlying cells show light background staining. Scale bars: $A-C, 50 \mu \mathrm{m} ; D-F, 30 \mu \mathrm{m}$.

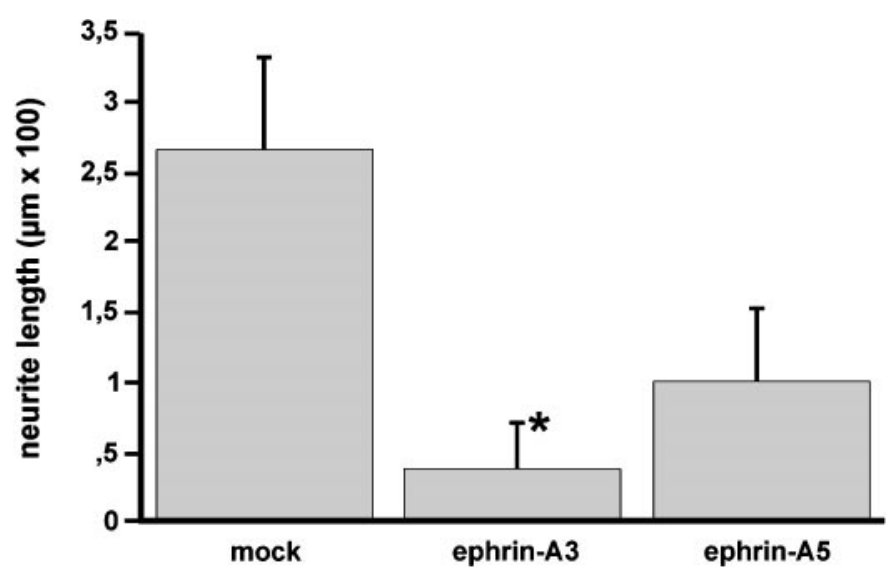

Figure 5. The results shown are the average length of 200 neurites measured in three independent experiments. The differences in entorhinal outgrowth length were statistically tested between ephrin-A3, ephrinA5, and mock-transfected cells ( ${ }^{*} p<0.001$; ANOVA; Mann-Whitney $U$ test). Error bars indicate SEM.

the explant was examined and photographed with FITC optics on an epifluorescence microscope.

Growth preferences for one or the other set of membrane stripes were evaluated using a three class system: (A) clear cut preference, with almost all of the fibers growing on one of the membrane lanes, (B) slight or moderate preference, with most fibers growing preferentially on one membrane lane, although others cross randomly, and (C) no choice or random outgrowth. The analysis of axonal choice behavior was performed as a double-blind experiment by three independent observers. Each observer scored the axon density on the different membrane stripes prepared in each experiment. In general, it was impossible to count individual entorhinal axons because of the variability in axon outgrowth density and fasciculation in some experiments. Rating classes A and B were scored 1 , and rating class $\mathrm{C}$ was scored 0 . The scores from each experimental condition were totaled, data from individual experiments were pooled, and $\chi^{2}$ tests were performed with an inter-rater reliability of $>90 \%$, which did not vary significantly in the different experiments performed.

\section{RESULTS}

EphA5 is present in the EC, and ephrin-A3 and ephrinA5 are expressed in hippocampus during development of the perforant pathway

To obtain clues about the function of EphA5 and its ligands ephrin-A3 and ephrin-A5 in the developing entorhinohippocampal formation, we used radioactive in situ hybridization to investigate the spatiotemporal distribution of their mRNA. At E17, an EphA5-specific probe detected strong signals in the cerebral cortex and in the hippocampal anlage (Fig. 2A). At P1, EphA5 expression was localized in the cortex, EC, subiculum, and CA1-CA3 (Fig. 2B). In the EC, layers II and III showed the strongest signal (Fig. 2E). Between P2 and P10, EphA5 expression was similar to that at $\mathrm{P} 1$ but with a stronger signal in the pyramidal layer of CA3 and weaker signals in the pyramidal layer of CA1, the granular layer of the dentate gyrus, and in the 

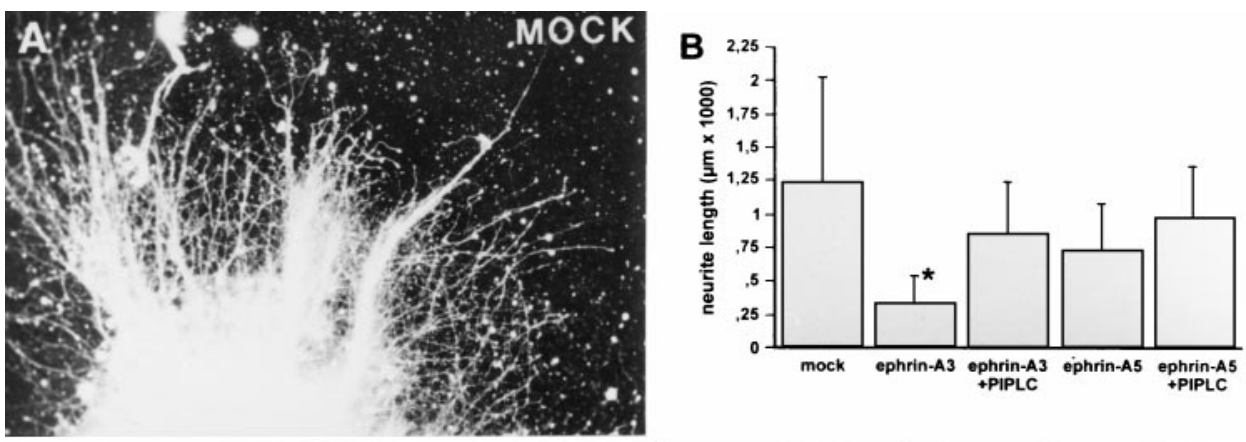

Figure 6. Inhibition of neurite outgrowth from entorhinal explants by ephrin-A3. Entorhinal explants were cultivated on a confluent membrane layer obtained from $3 \mathrm{~T} 3$ mocktransfected $(n=41)(A)$, ephrin-A3$(n=62)(C)$, and ephrin-A5- $(n=31)$ $(E)$ transfected cells. Neurites were visualized with a fluorescent vital dye, 5- and 6-carboxyfluorescein diacetate, succinimidyl ester. $D$, PI-PLC treatment of the obtained membranes $(n=$ 36) significantly prevents ephrin-A3 inhibition of entorhinal neurite outgrowth, whereas the effect of PI-PLC treatment on neurite outgrowth inhibition $(n=25)$ was not significant in the case of ephrin-A5 $(F)$. B, Quantification of entorhinal neurite length under the different conditions $( \pm$ SEM). The differences of entorhinal outgrowth length were significant between ephrin-A3 treatment and all other experimental conditions $\left({ }^{*} p<\right.$ 0.001; ANOVA; Mann-Whitney $U$ test). Scale bar, $100 \mu \mathrm{m}$.
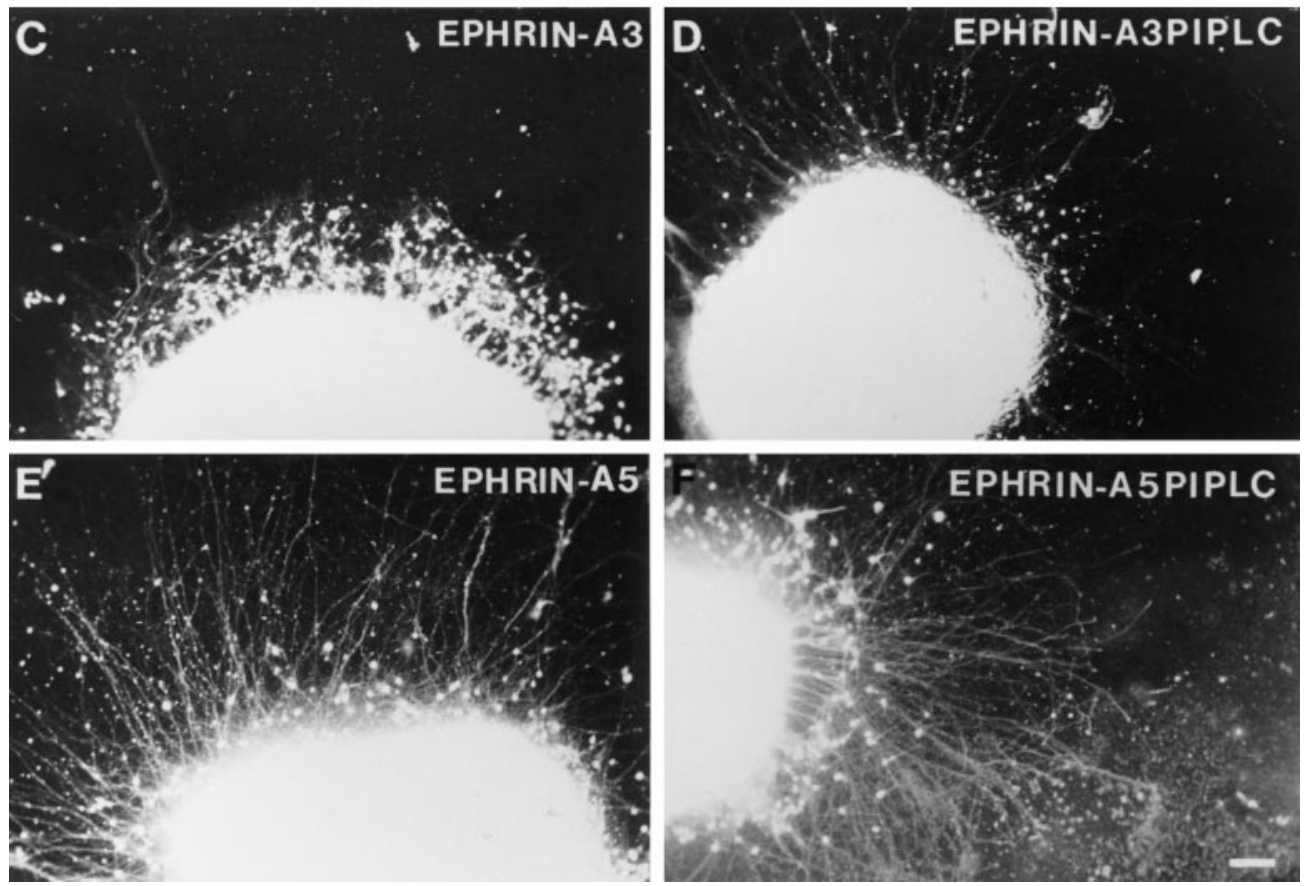

superficial layers of the EC (data not shown), consistent with previous observations (Zhang et al., 1997).

We further examined the expression of the EphA subfamily ligands ephrin-A3 and ephrin-A5 in the developing entorhinohippocampal system. At E17, ephrin-A3 was detected in the entire cortex and in the hippocampus (data not shown). At P2, ephrin-A3 mRNA was strongly expressed in the CA1-CA3 region and in the granular cell layer of the dentate gyrus (Fig. 2G). Ephrin-A5 mRNA was not detected during embryonic stages but could be localized in all CA pyramidal cell layers from P2 onward (Fig. 2H).

\section{Detection of the EphA5 ligand proteins in the hippocampus}

Because ephrin-A3 and ephrin-A5 mRNA were expressed in the hippocampus and EphA5 in the EC, we were interested in studying the localization of the EphA5 ligand proteins in the hippocampus in more detail. To detect EphA5 binding in the hippocampus, we stained embryonic and postnatal mouse brain sections with a ligand-affinity probe, which consisted of the extracellular domain of EphA5 fused in frame with a human placental AP, which binds to both ephrin-A3 and ephrin-A5. The septum, hypothalamus, and olfactory bulbus showed the strongest binding during embryonic stages, as shown previously by Zhang et al. (1996). Binding in the hippocampus was most prominent in the dendritic fields of the CA1 and dentate gyrus during postnatal stages (Fig. $2 K$ ). No staining was observed on the granular cell layer and in the outer molecular layers in the dentate gyrus. The strongest EphA5-AP binding was localized in the inner molecular layer. In CA1, the strongest EphA5-binding was detected in the stratum radiatum, whereas in the stratum lacunosum moleculare, EphA5-AP binding was weak.

\section{Entorhinal axons prefer membranes from the outer molecular layers of the hippocampus to membranes obtained from the inner molecular-granular layer}

When cell membranes of the outer molecular layer and the inner molecular-granular cell layer of the dentate gyrus were arranged in alternating stripes and explants of embryonic $\operatorname{EC}(n=36)$ were placed on the stripe carpet, the entorhinal axons showed a selective growth preference for the outer molecular layer membranes and did not grow on inner molecular-granular layer membranes (Fig. 3, Table 1). This preference was independent of the order of membrane application on the filter and thus not attributable to differences in the protein content of the lanes (Fig. 3B). Outgrowth of entorhinal neurites on uniform membrane carpets of the inner molecular-granular layer compared with the outer molecular layers of the dentate gyrus (stripes offered alone and not in alternating stripes) was also reduced (data not shown). 

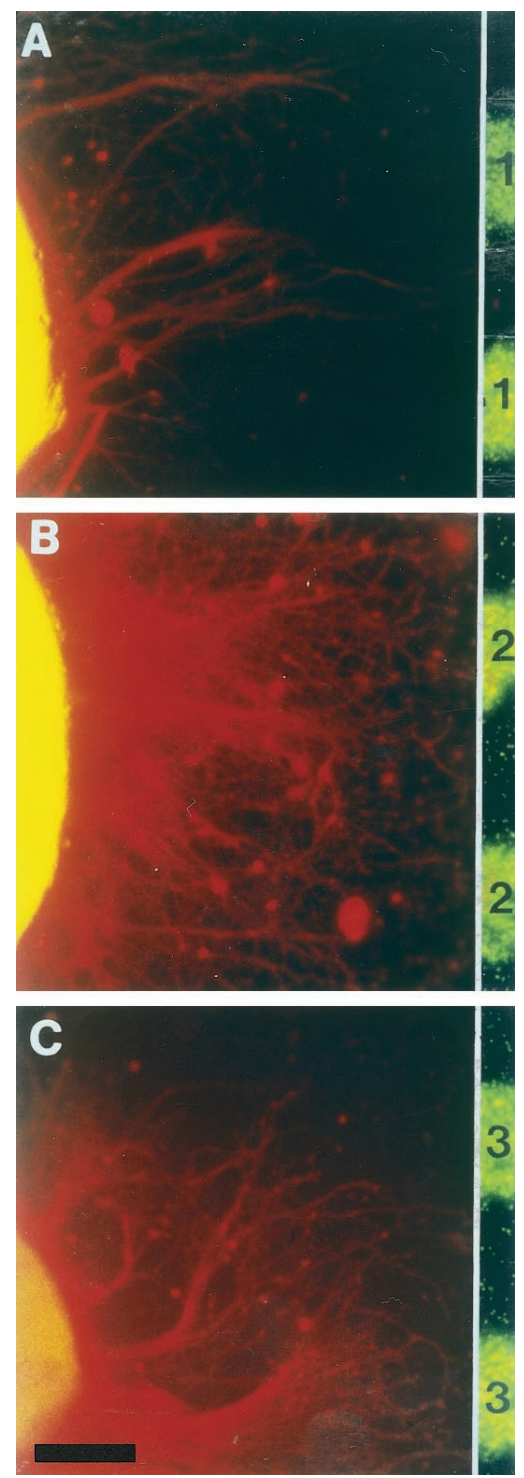

Figure 7. The growth preference of entorhinal neurites is influenced by ephrin-A3. A, Entorhinal neurites of E18 explants avoided ephrin-A3 membrane lanes $(n=15)$ but did not display any preferences when offered membrane lanes from ephrin-A5- $(n=12)(B)$ or mock- $(n=10)$ $(C)$ transfected NIH 3T3 cells. Neurites were stained as in Figure 5. 1, Ephrin-A3; 2, ephrin-A5; 3, mock-transfected 3T3 cells. Scale bar, 100 $\mu \mathrm{m}$.

\section{Outgrowth of entorhinal neurites is inhibited by ephrin-A3}

Entorhinal neurons from E18 rat brain were plated on a confluent monolayer of NIH 3 T3 cells expressing ephrin-A3 or ephrin-A5, or transfected with the expression vector alone (Fig. 4). The cell lines were constructed previously by Gao et al. (1996), and the expression of the ligands was further confirmed by EphA5-AP binding (Fig. 4A-C). Neurite extension from EC neurons was strongly inhibited by $3 \mathrm{~T} 3$ cells expressing ephrin-A3 (Figs. $4 F, 5$ ) and to a lesser extent by those expressing ephrin-A5 (Fig. 4E) compared with the length of entorhinal neurons on mocktransfected NIH $3 \mathrm{~T} 3$ cells (Fig. 4D). In contrast, neither ephrin-A3 nor ephrin-A5 inhibited neurite outgrowth from cerebellar neurons (data not shown). In accordance with the findings of Gao et al. (1996), the outgrowth of hippocampal neurons was
Table 2. Degree of entorhinal axon choice for laminin

\begin{tabular}{llllllc} 
& \multicolumn{9}{l}{ Category of axon choice } \\
\cline { 2 - 7 } Substrates & $\begin{array}{l}\text { Not clas- } \\
\text { sified }\end{array}$ & $\begin{array}{l}\text { No prefer- } \\
\text { ence }\end{array}$ & $\begin{array}{l}\text { Slight } \\
\text { prefer- } \\
\text { ence }\end{array}$ & $\begin{array}{l}\text { Clear } \\
\text { prefer- } \\
\text { ence }\end{array}$ & $n$ & Significance \\
\hline Ephrin-A3 & 0 & 1 & 1 & 13 & 15 & $p=0.001$ \\
Ephrin-A5 & 0 & 10 & 2 & 0 & 12 & NS \\
Mock & 1 & 9 & 0 & 0 & 10 & NS
\end{tabular}

Entorhinal explants were grown on laminin-precoated carpets with single membranes stripes obtained from control (3T3), ephrin-A3, or ephrin-A5 cells. Under these conditions, entorhinal axons did not grow on ephrin-A3 membranes. Classification of choice preferences is described in Material and Methods. $n$, Number of explants; L, laminin; NS, not significant.

significantly inhibited by both ephrin-A3 and ephrin-A5 (data not shown).

Similar effects were observed with entorhinal explants cultivated on uniform membranes obtained from cells expressing ephrin-A3 $(n=62)$ or ephrin-A5 $(n=31)$, or transfected with the expression vector alone $(n=41)$ (Fig. 6). In particular, the outgrowth of entorhinal neurites was strongly inhibited by ephrin-A3 membranes (Fig. 6C), whereas membranes obtained from cells expressing ephrin-A5 (Fig. 6E) and control cells (Fig. $6 A$ ) had significantly less effect on entorhinal fiber extension. Because ephrin-A3 and ephrin-A5 can be removed from the membrane preparation by PI-PLC treatment, we analyzed the effect of PI-PLC treatment on ephrin-A3 inhibition of entorhinal neurite outgrowth $(n=36)$. Removal of ephrin-A3 from the membranes restored neurite elongation from entorhinal explants (Fig. 6D). Entorhinal outgrowth was not significantly affected on membranes obtained from ephrin-A5-transfected NIH 3T3 cells that had been treated with PI-PLC (Fig. 6F). This observation suggests that ephrin-A3 in particular selectively and specifically inhibits entorhinal axon outgrowth.

\section{The extension and growth preference of EC neurites is controlled by ephrin-A3}

In the stripe assay, EC explants were allowed to grow on membrane stripes prepared from stably transfected 3T3 cells expressing ephrin-A3 $(n=15)$, ephrin-A5 $(n=12)$, or controls $(n=10)$ (Fig. 7, Table 2).

Given the choice between a membrane lane from mocktransfected cells or laminin, entorhinal neurites did not display any preference and crossed lane borders freely (Fig. 7C, Table 2). Even in the choice situation between ephrin-A5 membrane lanes and laminin lanes, extending EC neurites displayed a random growth pattern (Fig. 7B, Table 2). However, entorhinal neurites specifically avoided membranes prepared from ephrin-A3expressing 3T3 cells (Fig. 7A, Table2). These results support the finding that extending EC neurites are selectively repelled by ephrin-A3.

\section{DISCUSSION}

Our studies demonstrate that entorhinal axons are responsive to ephrin-A3 at the time when entorhinal fibers invade the molecular layer of the dentate gyrus in vivo. Axons of the perforant pathway have entered their target area in the molecular layer of the dentate gyrus at E19, shortly before birth (Super and Soriano, 1994). EphA5 mRNA expression was found from E17 onward in layers II and III of the EC, the origin of neurons forming the perforant pathway. Our in situ hybridization data showed that 


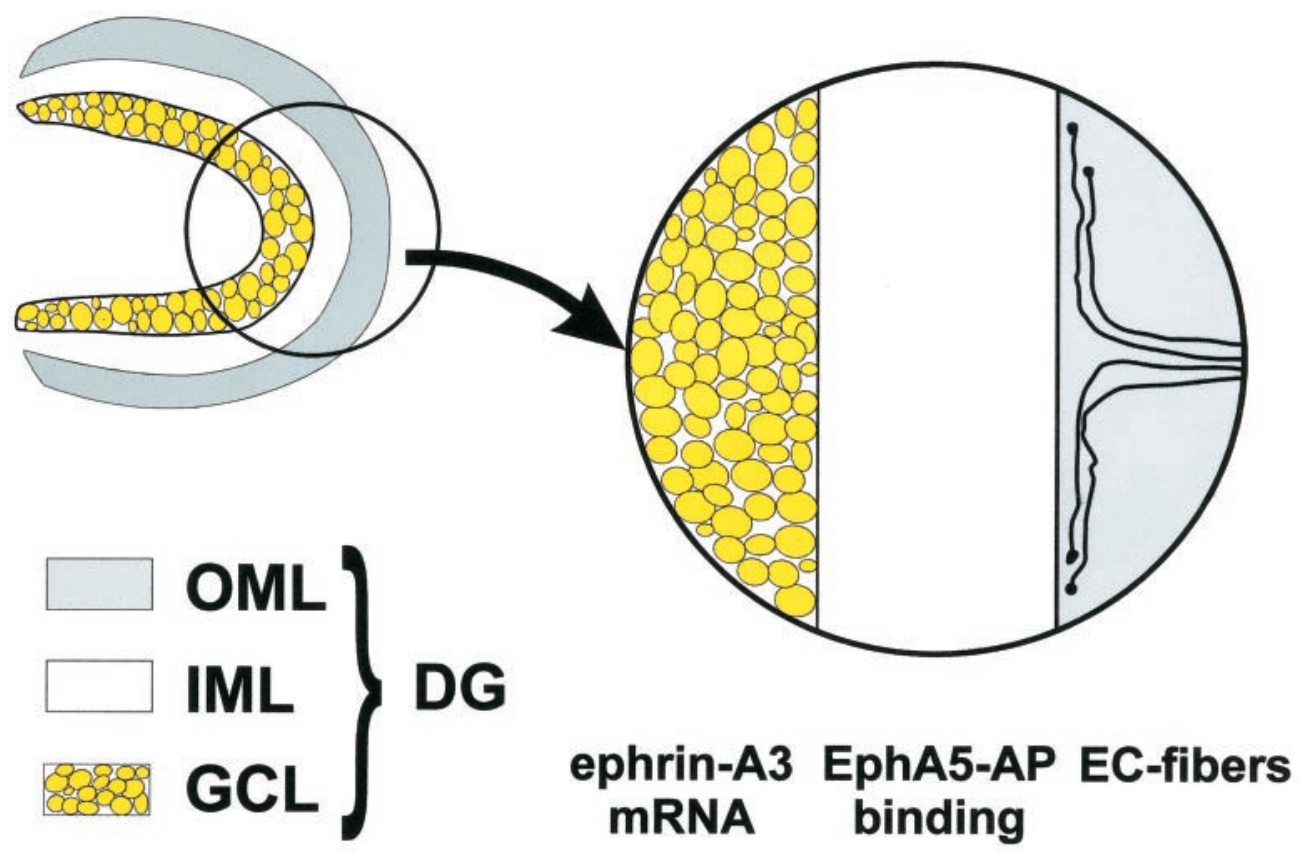

Figure 8. Schematic illustration of the dentate gyrus with granular cell layer $(G C L)$, inner molecular layer $(I M L)$, and outer molecular layer $(O M L)$. Ephrin-A3 mRNA is expressed in the granular cell layer, whereas Eph A5-AP fusion protein binding that detects ephrin A ligands is present in the inner molecular layer. Axons of the entorhinal cortex do not enter the inner molecular layer and branch in the outer molecular layer.
ephrin-A3 mRNA is expressed in the granular cell layer of the dentate gyrus. In addition, the ligand protein was detected using EphA5-AP binding in the inner molecular layer of the dentate gyrus, a region not invaded by EC neurites from layer II in vivo. Because EphA5 interacts with multiple ligands in vitro but only ephrin-A3 is present in the dentate gyrus, the EphA5-AP binding data probably reflects the distribution of this guidance cue in the dentate gyrus. Several observations indicate that ephrin-A3 has a specific effect in entorhino-hippocampal axon targeting. First, the neurite and outgrowth explant assay only displayed a significant inhibitory effect by ephrin-A3 but not by ephrin-A5 or controls. Second, digestion of the GPI-anchor of ephrin-A3 by PI-PLC treatment abolished this effect. Third, the EphA5 receptor is synthesized in EC neurons, and soluble AP-tagged EphA5 binds strongly to the inner molecular layer. Thus, entorhinal fiber outgrow th to the inner molecular layer of the dentate gyrus would be repelled, whereas the outer molecular layer would be permissible for these ingrowing axons.

The afferent connections of the hippocampus and its entorhinal input, the perforant and alvear pathways, represent a well established model for the analysis of target-specific pathfinding, termination, and reinnervation (Frotscher and Heimrich, 1993; Li et al., 1993, 1994, 1995; Woodhams 1993; Woodhams and Atkinson, 1996; Frotscher et al., 1997). It was shown that the molecular signals necessary for the formation of an entorhino-dentate projection are present in hippocampal tissue maintained in organotypic coculture with explants of the EC (Frotscher and Heimrich, 1993; Li et al., 1993; Woodhams and Atkinson, 1996). Heterochronic slice culture experiments and transplantation of embryonic entorhinal cells to adult hippocampus have also outlined the presence of positional guidance cues in the adult hippocampus (Zhou et al., 1989; Li et al., 1995). These experiments indicated that lamina-specific molecules in the hippocampal fields play important roles in the formation of layer-specific afferent projections. But none of these studies provided information about the mechanisms entorhinal axons use to select their original pathways and target fields.

Del Río et al. (1997) showed that ablation of Cajal-Retzius cells influenced the ingrowth of entorhinal fibers into the molecular layer of the dentate gyrus. This finding suggests that, in addition to repulsive guidance factors such as ephrin-A3, which is expressed in the granular cell layer of the dentate gyrus, CajalRetzius cells localized in the molecular layer of the dentate gyrus produce an attractive factor that guides entorhinal neurons toward the molecular layer. Superculturing of prelabeled entorhinal neurons or membranes on hippocampal slice preparations led to the observation of lamina-specific adhesion in the termination zones of the entorhino-hippocampal formation (Förster et al., 1998). These adhesion experiments documented the presence of membrane-bound adhesive properties in the outer molecular layer of the dentate gyrus and the absence of these activities in the granular cell layer, a zone that is not targeted by most entorhinal axons in vivo. Our data and the observations of Del Río et al. (1997) and Förster et al. (1998) indicate the presence of attractive adhesive and repulsive properties in the developing dentate gyrus.

The laminated expression of EphA5 ligands might repel the ingrowth of the entorhino-hippocampal projection toward the inner molecular layer of the dentate gyrus (see Fig. 8 for schematic illustration). We were able to demonstrate that entorhinal axons prefer membrane extracts from the outer molecular layer of the hippocampus to membrane preparations obtained from the inner molecular-granular layer. The use of outgrowth and choice assays made it possible to show that the extension and guidance of entorhinal neurites are strongly influenced by the membranebound molecule ephrin-A3. All these findings lead us to propose that Eph receptors and ligands participate in the developmental mechanisms underlying the termination of the lamina-specific entorhino-hippocampal projection.

Because EphA5, ephrin-A3, and ephrin-A5 are all expressed in the hippocampal formation, these molecules might also be involved in the guidance of intrahippocampal projections. However, it will require further investigation to determine in more detail whether subpopulations of hippocampal neurons respond differentially to these and other guidance cues of the Eph family. It will 
also be interesting to analyze the phenotype of hippocampal projections in ephrin-A3 and ephrin-A5 knock-out mice.

It should also be emphasized that the hippocampus is well known for structural remodeling and for lamina-specific sprouting after lesioning its different afferent inputs (for review, see Frotscher et al., 1997). The continuous expression of EphA5, ephrin-A3, and ephrin-A5 in the hippocampal system during adulthood suggests that these molecules might also play a role in synaptic plasticity.

In summary, our observations indicate that ephrin-A3 acts as a repulsive signal that helps to pattern the perforant pathway by limiting the growth of entorhinal fibers to the outer molecular layer of the dentate gyrus. It may also perform a similar function for intrahippocampal connections. However, the laminated distribution of hippocampal afferents is probably the result of a cooperation between both attractive and repulsive guidance factors. Further studies have to address the question of how the temporal and spatial expression patterns of these factors manage to lead the ingrowing afferents to their appropriate target area.

\section{REFERENCES}

Bechmann I, Nitsch R (1997) Astrocytes and microglial cells incorporate degenerating fibers following entorhinal lesion: a light, confocal, and electron microscopical study using a phagocytosis-dependent labeling technique. Glia 20:145-154.

Carpenter MK, Shilling H, VandenBos T, Beckmann MP, Cerretti DP, Kott JN, Westrum LE, Davison BL, Fletcher FA (1995) Ligands for EPH-related tyrosine kinase receptors are developmentally regulated in the CNS. J Neurosci Res 42:199-206.

Ciossek T, Lerch MM, Ullrich A (1995) Cloning, characterization, and differential expression of MDK2 and MDK5, two novel receptor tyrosine kinases of the eck/eph family. Oncogene 11:2085-2095.

Culotti JG, Kolodkin AL (1996) Functions of netrins and semaphorins in axon guidance. Curr Opin Neurobiol 6:81-88.

Del Río JA, Heimrich B, Borrell V, Forster E, Drakew A, Alcantara S, Nakajima K, Miyata T, Ogawa M, Mikoshiba K, Derer P, Frotscher M, Soriano E (1997) A role for Cajal-Retzius cells and reelin in the development of hippocampal connections. Nature 385:70-74.

Flanagan JG, Vanderhaeghen P (1998) The ephrins and Eph receptors in neural development. Annu Rev Neurosci 21:309-345.

Förster E, Kaltschmidt C, Deng J, Cremer H, Deller T, Frotscher M (1998) Lamina-specific cell adhesion on living slices of hippocampus. Development 125:3399-3410.

Friedman GC, O’Leary DD (1996) Eph receptor tyrosine kinases and their ligands in neural development. Curr Opin Neurobiol 6:127-133.

Frotscher M, Heimrich B (1993) Formation of layer-specific fiber projections to the hippocampus in vitro. Proc Natl Acad Sci USA 90:10400-10403.

Frotscher M, Heimrich B, Deller T (1997) Sprouting in the hippocampus is layer-specific. Trends Neurosci 20:218-223.

Gao PP, Zhang JH, Yokoyama M, Racey B, Dreyfus CF, Black IB, Zhou R (1996) Regulation of topographic projection in the brain: Elf-1 in the hippocamposeptal system. Proc Natl Acad Sci USA 93: 11161-11166.

Holt CE, Harris WA (1998) Target selection: invasion, mapping and cell choice. Curr Opin Neurobiol 8:98-105.

Kozlosky CJ, VandenBos T, Park L, Cerretti DP, Carpenter MK (1997) LERK-7: a ligand of the Eph-related kinases is developmentally regulated in the brain. Cytokine 9:540-549.

Li D, Field PM, Starega U, Li Y, Raisman G (1993) Entorhinal axons project to dentate gyrus in organotypic slice co-culture. Neuroscience 52:799-813.

Li D, Field PM, Yoshioka N, Raisman G (1994) Axons regenerate with correct specificity in horizontal slice culture of the postnatal rat entorhino-hippocampal system. Eur J Neurosci 6:1026-1037.
Li D, Field PM, Raisman G (1995) Failure of axon regeneration in postnatal rat entorhinohippocampal slice coculture is due to maturation of the axon, not that of the pathway or target. Eur J Neurosci 7:1164-1171.

Maisonpierre PC, Barrezueta NX, Yancopoulos GD (1993) Ehk-1 and Ehk-2: two novel members of the Eph receptor-like tyrosine kinase family with distinctive structures and neuronal expression. Oncogene 8:3277-3288.

Martone ME, Holash JA, Bayardo A, Pasquale EB, Ellisman MH (1997) Immunolocalization of the receptor tyrosine kinase EphA4 in the adult rat central nervous system. Brain Res 771:238-250.

Mori T, Wanaka A, Taguchi A, Matsumoto K, Tohyama M (1995) Differential expressions of the eph family of receptor tyrosine kinase genes (sek, elk, eck) in the developing nervous system of the mouse. Brain Res Mol Brain Res 29:325-335.

Simon DK, O'Leary DD (1992) Responses of retinal axons in vivo and in vitro to position-encoding molecules in the embryonic superior colliculus. Neuron 9:977-989.

Steward O, Scoville SA (1976) Cells of origin of entorhinal cortical afferents to the hippocampus and fascia dentata of the rat. J Comp Neurol 169:347-370.

Super H, Soriano E (1994) The organization of the embryonic and early postnatal murine hippocampus. II. Development of entorhinal, commissural, and septal connections studied with the lipophilic tracer DiI. J Comp Neurol 344:101-120.

Tamamaki N, Nojyo Y (1993) Projection of the entorhinal layer II neurons in the rat as revealed by intracellular pressure-injection of neurobiotin. Hippocampus 3:471-480.

Taylor V, Miescher GC, Pfarr S, Honegger P, Breitschopf H, Lassmann H, Steck AJ (1994) Expression and developmental regulation of Ehk-1, a neuronal Elk-like receptor tyrosine kinase in brain. Neuroscience 63:163-178.

Tessier-Lavigne M, Goodman CS (1996) The molecular biology of axon guidance. Science 274:1123-1133.

Walter J, Henke Fahle S, Bonhoeffer F (1987a) Avoidance of posterior tectal membranes by temporal retinal axons. Development 101:909-913.

Walter J, Kern Veits B, Huf J, Stolze B, Bonhoeffer F (1987b) Recognition of position-specific properties of tectal cell membranes by retinal axons in vitro. Development 101:685-696.

Witter MP (1993) Organization of the entorhinal-hippocampal system: a review of current anatomical data. Hippocampus 3:33-44.

Woodhams PL (1993) Laminar and region-specific cell surface markers in the entorhinal cortex and hippocampus. Hippocampus 3:183-189.

Woodhams PL, Atkinson DJ (1996) Entorhinal axons perforate hippocampal field CA3 in organotypic slice culture. Brain Res Dev Brain Res 95:144-147.

Zhang JH, Cerretti DP, Yu T, Flanagan JG, Zhou R (1996) Detection of ligands in regions anatomically connected to neurons expressing the Eph receptor Bsk: potential roles in neuron-target interaction. J Neurosci 16:7182-7192.

Zhang JH, Pimenta AF, Levitt P, Zhou R (1997) Dynamic expression suggests multiple roles of the eph family receptor brain-specific kinase (Bsk) during mouse neurogenesis. Brain Res Mol Brain Res 47:202-214.

Zhou CF, Li Y, Raisman G (1989) Embryonic entorhinal transplants project selectively to the deafferented entorhinal zone of adult mouse hippocampi, as demonstrated by the use of Thy- 1 allelic immunohistochemistry. Effect of timing of transplantation in relation to deafferentation. Neuroscience 32:349-362.

Zhou R (1997) Regulation of topographic projection by the Eph family receptor Bsk (EphA5) and its ligands. Cell Tissue Res 290:251-259.

Zhou R (1998) The Eph family receptors and ligands. Pharmacol Ther 77:151-181.

Zhou R, Copeland TD, Kromer LF, Schulz NT (1994) Isolation and characterization of Bsk, a growth factor receptor-like tyrosine kinase associated with the limbic system. J Neurosci Res 37:129-143. 